\title{
O legado do Departamento de Sociologia de Chicago (1920- 1930) na constituição do interacionismo símbólico
}

Carlos Benedito Campos Martins ${ }^{1}$

Resumo: O artigo ressalta que os integrantes do Departamento de Sociologia da Universidade de Chicago nos anos 1920 não possuíam a intenção de criar uma nova vertente sociológica. O termo interacionismo simbólico jamais foi utilizado pelos seus participantes para designar os trabalhos que estavam realizando. No entanto, as pesquisas empíricas e a reflexão realizada no interior desse Departamento a respeito do processo de interação entre indivíduo e sociedade pavimentou o caminho para o surgimento, em momento posterior, de uma nova postura explicativa da vida social. Somente no final da década de 1930, o trabalho sociológico que vinha ali sendo realizado foi codificado em um corpus de princípios teóricos e nomeado enquanto tal como interacionismo simbólico.

Palavras-chave: Departamento de Sociologia de Chicago, Pesquisa Empírica e Teoria, Relação Indivíduo e Sociedade, Interacionismo Simbólico.

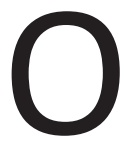

trabalho Alvin Gouldner, The Coming Crisis of Western Sociology, captou de modo eloquente o impacto dos movimentos de contestação cultural, política e social que ocorreram no final dos anos 1960, no interior do campo da sociologia norte-americana. Em sua visão, o surgimento, naquele momento, de uma cultura produzida por jovens universitários engendrou uma nova estrutura de sentimentos entre seus participantes que se mostrou hostil aos valores utilitaristas que impregnavam a vida cotidiana da sociedade norte-americana. Sua análise apreendeu, de forma penetrante, a atitude crítica de jovens sociólogos norte-amaricanos ao modelo funcionalista formulado por Talcott Parsons, apresentado inicialmente em 1937, em sua obra The Structure of Social Action, e ampliado em 1951, com a publicação do seu trabalho The Social System. Ao mesmo tempo em que delineou os contornos do apogeu e do declínio da dominação da análise estrutural-funcional capiteneada por Parsons - que galvanizou não apenas parte significativa da sociologia norteamericana, mas que desfrutou também uma posição destacada em várias sociologias nacionais -, o trabalho de Alvin Gouldner destacou simultaneamente a
1. Professor Titular do Departamento de Sociologia da Universidade de Brasília. E-mail: carlosb@ unb.br 
emergência de novos modelos teóricos, orientados por microteorizações que enfatizavam o caráter instável da sociedade e ressaltavam a centralidade da negociação do ator com as múltiplas instituições existentes na vida social (GOULDNER, 1970).

Ao salientar o surgimento de teorias alternativas ao funcionalismo em geral e, em particular, à versão elaborda por Talcott Parsons, o livro de Alvin Goudner destacou a sociologia de Erving Goffman. Na avaliação de Alvin Gouldner, a sociologia de Erving Goffman, que se encontrava naquele período numa fase de plena elaboração, reintroduziu na cena da vida social a presença efetiva dos homens, realizando suas ações cotidianas, ansiosos e torturados diante do incessante e interminável trabalho dramatúrgico desempenhado por eles, cuja preocupação fundamental consistia em projetar uma imagem convincente de si para os outros, deslocando para o segundo plano as sólidas estruturas sociais, que ocupavam uma posição saliente na análise funcionalista elaborada por Talcott Parsons. Nesse sentido, o trabalho de Alvin Gouldner destacou a existência do interacionismo simbólico e sua relação indireta com o Departamento de Sociologia da Universidade de Chicago, mesmo estando consciente da complexa e tensa interação que existiu entre Goffman e a tradição interacionista. Nos anos 1970, com o declínio do funcionalismo, a corrente do Interacionismo Simbólico e suas diferentes versões passaram a ocupar uma centralidade nas discussões teóricas, metodológicas e de pesquisas no contexto da sociologia, de tal forma que a intensidade de sua presença no debate sociológico nesse período poderia sugerir a falsa impressão de que se tratava do surgimento de uma nova tendência explicativa. No entanto, o interesse despertado em torno do interacionismo simbólico naquele momento, de certa forma, constituía uma ironia da história intelectual da sociologia, uma vez que suas bases iniciais foram assentadas durante os anos 1920, no interior do Departamento de Chicago, e prosperou nas décadas posteriores (FINE, 1993).

O presente artigo parte do pressuposto de que o gupo pioneiro de docentes e filósofos que aglutinou em torno do Departamento de Sociologia da Universidade de Chicago, nos anos 1920, não possuía a intenção de formalizar um programa de investigação que pudesse desembocar diretamente na criação de uma escola sociológica. Nessa direção, distanciou-se da ambição de construir um autoembasamento de uma teoria sistemática sobre a vida social e também não demonstrou interesse em codificar, em um conjunto de normas, os procedimentos metodológicos que pautaram o processo de investigação que estavam realizando. Deve-se acrescentar, também, que a pluralidade de formação intelectual e a diversidade metodológica dos seus participantes tão pouco caminhou na direção de estabelecer deliberadamente uma nova corrente explicativa no interior do campo da sociologia. No entanto, os trabalhos exemplares de 
pesquisa produzidos sob a égide do Departamento de Sociologia de Chicago, juntamente com o alcançe da reflexão realizada por determinados filósofos norte-americanos sobre a problemática do conhecimento e a respeito do processo de interação entre indivíduo e sociedade pavimentou o caminho para a emergência de uma nova postura explicativa da vida social que foi codificada posteriormente, ou seja, no final da década de 1930, em um corpus de princípios teóricos e nomeada, enquanto tal, como interacionismo simbólico. Igualmente, a noção da existência da "escola de Chicago" - jamais reivindicada pelos pioneiros do Departamento de Sociologia de Chicago - também foi construída num momento posterior, num complexo processo que envolveu diferentes atores sociais, tais como: novas gerações de docentes e pesquisadores engendrados em seu interior que passaram a reivindicar um estilo intelectual próprio no processo de construção do conhecimento sociológico, bem como por parte de críticos do predomínio da presença do Departamento de Sociologia de Chicago no contexto da sociologia norte-americana e também por pesquisadores de diferentes países interessados em recuperar sua contribuição para a sociologia contemporânea. Tudo leva a crer que existem visíveis diferenças de significado entre o empreendimento efetivo levado a cabo pelos pioneiros da construção do Departamento de Chicago, na década de 1920, e as variadas interpretações realizados por esses atores nas décadas seguintes (ABBOT, 1999; GUSFIELD, 1995, p. ix-xv; HARVEY, 1987; BULMER, 1984, SCHWENDINGER, 1974; SMITH, 1988).

As condições que possibilitaram o Departamento de Sociologia de Chicago tornar-se um centro criativo, inovador e ocupar uma posição dominante na sociologia norte-americana - cujos desdobramentos reverberaram no conhecimento sociológico em décadas posteriores - colocam em evidência o entrelaçamento de uma complexa constelação de fenômenos, tal como o acelerado processo de industrialização, urbanização e imigração que perpassava a sociedade norte-americana no final do século XIX e seu impacto na cidade de Chicago. Ao memo tempo, o processo de reestruturação do sistema de ensino universitário norte-americano, que ocorreu no final do século XIX, impulsionou simultaneamente a fundação de novas universidades e a criação de novos departamentos, o que favoreceu a atividade de pesquisa e abriu um considerável espaço para o desenvolvimento da sociologia. Não menos importante na estruturação dos trabalhos de pesquisa realizados no interior do Departamento de Sociologia de Chicago foi o esforço de integrar a atividade teórica com a investigação empírica que reflete a presença marcante entre seus participantes da filosofia prgamática que insistia na unidade entre teoria e ação, entre reflexão e mundo real. Apesar da posição destacada que ocupou no campo da sociologia norteamericana na década de 1920 e do vigor da produção intelectual realizada pelas novas gerações de docentes e de alunos que o integraram posteriormente - que 
contribuíram para o avanço da pesquisa sociológica em temas como processo de socialização, sociologia criminal, sociologia urbana, universo das profissões etc. -, ocorreu um relativa invisibilidade da presença do Departamento de Sociologia de Chicago no contexto da sociologia norte-americana que começou a ser interrompida a partir do final da década de 1960 (SMITH \& JORSEN, 2009; ABBOT, 1999; CHAPOULIE, 2001; KURTZ, 1994).

Em três décadas, ou seja, entre o período de 1850 a 1880, a cidade de Chicago passou a ocupar a quarta posição em termos de tamanho na sociedade norteamericana, absorvendo uma população de cerca de 500 mil habitantes. Nesse período, transformou-se de um importante entreposto comercial e processador de grãos em um dinâmico centro industrial e um ponto de atração e de entrada de imigrantes europeus procedentes da Irlanda, Polônia, Suécia, Dinamarca, Alemanha, Ucrânia, Rússia, negros e brancos pobres do sul dos Estados Unidos, de tal forma que, em 1910, sua população atingiu a cifra de 2,1 milhões de habitantes. As mudanças de sua estrutura produtiva e o incremento do fluxo migratório impulsionou uma imponente arquitetura, multiplicou o número de subúrbios, engendrou um expressivo processo de segregação étnico-social e foi acompanhada, também, por tensões raciais, surgimento de gangues e de corrupção da máquina política dominada pelo Partido Democrata. A cidade de Chicago, ao se constituir como uma metrópole impessoal, marcada por um agudo processo de desigualdade social - diversa culturalmente, comportando uma variada gama de estilos de vida que plasmava a rotina de seus habitantes e desafiava o processo de adaptação da sua população migrante -, despertou a atenção intelectual de diversos atores sociais interessados em desvendar e reformar suas estuturas sociais e especialmente dos sociólogos (BRANDÃO LOPES, 2005, p. 24-52; VELHO, 2005, p. 54-66; SHILLS, 1988; MAYER \& WADE, 1969).

Enquanto as centenárias universidades europeias não ofereciam um terreno propício para o processo de desenvolvimento da sociologia, as instituições acadêmicas norte-americanas vivenciavam, no início dos anos 1900, um processo em sentido oposto. A significativa reestruturação do sistema de ensino superior norte-americano, iniciada no final do século XIX - que exerceu um profundo impacto na emergência do Departamento de Sociologia de Chicago -, foi, em larga medida, influenciada pelo modelo de universidade concebido e implantado por Humbolt nas instituições alemãs a partir de 1810, no qual o ensino e a pesquisa eram concebidos como atividades indissociáveis. Em larga medida, o modelo humboltiano de universidade constituiu uma fonte de referência tanto no processo de transformação de antigos colleges norte-americanos criados na época colonial em universidades do porte acadêmico de Harvard, Columbia, Yale, etc., quanto na criação de novas universidades. O surgimento de universidades de pesquisas no contexto norte-americano, nesse período, foi impulsionado 
pela crença de sua elite política e empresarial de que a produção de novos conhecimentos constituía um fator estratégico na dinâmica do desenvolvimento econômico e do poder militar e também um elemento essencial para enfrentar os problemas sociais que surgiram no bojo de um acelerado processo de industrialização e urbanização. Nesse contexto, a Universidade Johns Hopkins foi criada, inicialmente, para oferecer apenas cursos de pós-graduação e o surgimento do MIT e da Universidade de Cornell foram pioneiros no sentido de direcionar a universidade no sentido de produzir conhecimentos práticos em vários domínios da vida social. Nessa direção, o Morril Act de 1862 destinou terrenos pertencentes ao governo federal para a criação de universidades estaduais com o propósito de incentivar a produção de conhecimentos práticos (REUBEN, 1995).

A sociologia norte-americana que vinha sendo praticada por uma gama de intelectuais que não possuíam formação na disciplina - uma vez que inexistiam cursos universitários de sociologia na época - beneficiou-se do processo de reestruturação do campo acadêmico norte-americano que lhe abriu reais possibilidades de desenvolvimento institucional. A participação de fundações privadas de pesquisa que passaram a apoiar o desenvolvimento científico de instituições já existentes e também o surgimento de novos estabelecimentos de ensino e pesquisa desempenharam um vetor estratégico no processo de institucionalização da sociologia no contexto norte-americano. Dessa forma, determinadas universidades norte-americanas que institucionalizaram a atividade de pesquisa contaram com expressivos aportes financeiros da Fundação Rockefeller, através da Fundação Laura Spelman Rockefeller, que criou, em 1923, o Social Science Research Council. A Universidade de Chicago nasceu sob o patrocínio de uma associação encarregada de apoair os estabelecimentos escolares batistas e com o apoio financeiro de John Rockefeller, que destinou a quantia de 1 milhão de dólares para sua fundação. A nova universidade, que abriu suas portas em 1892, não impôs condição de crença religiosa no recrutamento de seu pessoal docente, nem na admissão de estudantes, embora seu conselho de administração fosse dominado pela congregação batista (CHAPOULIE, 2001; RINGER, 1969; BULMER, 1982; LUCAS, 1994; GEIGER, 1986; CLARK, 1973).

Ao inaugurar a Universidade de Chicago, em 1892, seu presidente, William Harper, manifestou claramente que a nova instituição assumiu como sua tarefa acadêmica primordial a realização de atividade de pesquisa e, num segundo plano, as atividades de ensino. A partir do apoio financeiro fornecido pela Fundação Rockefeller, a Universidade de Chicago construiu uma sólida infraestrutura de recursos materiais e humanos propícios ao desenvolvimento de suas atividades acadêmicas e, especialmente, à prática da pesquisa. Dessa forma, nos anos 1920, não apenas o seu Departamento de Sociologia tornou-se um centro de referência no universo acadêmico norte-americano e internacional, mas também 
os departamentos de filosofia, ciência política, economia, etc. Quando William Harper convidou Albion Small para organizar o Departamento de Sociologia da nova universidade, tinha em mente que a exploração de novas disciplinas que até então não haviam sido incorporadas nas instituições de ensino norte-americanas - tal como ocorria com a sociologia - constituía uma estratégia oportuna para dinamizar uma universidade recém-criada, de forma que a sociologia não teve que lutar pela sua existência diante de disciplinas mais consolidadas, tal como a economia política, e pôde com relativa facilidade demarcar seu próprio campo de atuação (STOR \& BUNNET, 1966).

A embrionária sociologia norte-americana do século XIX foi marcada por uma profunda preocupação pela ideia de progresso e de reforma social que conduziu vários de seus praticantes a assumirem, em maior ou menor escala, pressupostos evolucionistas e acatar a ideia de que a sociologia poderia adotar os mesmos pressupostos e procedimentos das ciências naturais. A formação religiosa protestante de vários sociólogos - alguns deles foram filhos de pastores protestantes e tornaram-se clérigos - os impulsionou a aderir aos movimentos de reforma social e estabelecer relações com diferentes atores que integravam os movimentos reformistas, tais como advogados, educadores, filantropistas, etc. A fundação da American Social Science, em 1865, procurou congregar esses atores com o propósito de imprimir uma abordagem mais objetiva aos diversos problemas sociais que emergiram no bojo de uma sociedade em franco processo de mudança social. Nesse contexto, ocorreu a realização de vários surveys apoiados por organizações filantrópicas e por fundações de pesquisa, tal como a Russel Sage Foundation, que levantaram uma ampla gama de informações empíricas sobre a vida social norte-americana naquele momento, enfocando questões, tais como pobreza, condições de moradia, crime, acidentes industriais, educação pública, etc. Os surveys sobre as condições sociais de vida urbana contribuíram para despertar a atenção dos sociólogos sobre da existência desse rico material empírico e, indiretamente, desempenharam um papel importante para preparar o caminho para o florescimento de uma sociologia urbana levada a cabo no interior do Departamento de Sociologia de Chicago (CALHOUN, 2007, p. 1-38; FARIS, 1967).

O Departamento de Sociologia da Universidade de Chicago iniciou suas atividades no mesmo ano de criação da instituição, contanto com um corpo docente reduzido oferecendo cursos de graduação e pós-graduação. Tornou-se o primeiro departamento acadêmico de sociologia na esteira do processo de institucionalização da sociologia norte-americana, seguido posteriormente por Columbia, Kansas, Michigan e, décadas mais tarde, por Harvard, Princeton, Johns Hopkins, etc. A constituição do Departamento representou um empreendimento acadêmico ousado, uma vez que a maioria do corpo docente que o integrou em 
sua fase inicial não possuía formação em sociologia. Seu fundador, Albion Small, que permaneceu como seu responsável até 1925, estudou história em Berlim. Após obter seu doutoramento em história, na Universidade Johns Hopkins, tornou-se professor dessa disciplina no Colby College e, gradativamente, interessou-se pela sociologia. A primeira geração do corpo docente do Departamento de Sociologia de Chicago, no período de 1920-1930, foi integrada por Albion Small, Charles Henderson, Graham Taylor, Charles Zueblin, George Vincent e William Thomas, sendo que os dois últimos realizaram seu doutorado no próprio Departamento de Sociologia. Outras figuras acadêmicas importantes nessa primeira geração, que não estavam ligadas diretamente ao Departamento, mas que tiveram impacto na sua produção intelectual, foram John Dewey e George Herbert Mead, que pertenciam ao Departmento de Filosofia da Universidade de Chicago, bem como Charles Cooley, que exercia sua função docente na Universidade de Michigan; Thorstein Veblen, que foi professor de economia durante quatorze anos em Chicago, e Jane Addams, que liderava um movimento de reforma social a partir da Hull House. Nos anos 1920, o corpo de professores do Departamento compreendia Albion Small, Robert Park, Ernest Burguess, Ellsworth Faris, e formou uma plêiade de novos pesquisadores, entre os quais se destacam Robert McKenzie, Nels Anderson, Frederic Thrasher, Robert Redfield, Ruth Shonle Cavan, etc. Outros docentes da Universidade mantinham também conexões intelectuais com o Departamento, destacadamentre Charles Merriam, L. L. Thurstone, Harold Lasswell e Shailer Mathews (KURTZ, 1984; FARIS, 1967).

As vozes de Herbert Spencer, Lester Ward e William Summer possuíam uma expressiva ressonância na sociologia norte-americana no momento da edificação do Departamento de Sociologia de Chicago. Embora alguns de seus integrantes possuíssem simpatias pelas ideias evolucionistas - tal como Albion Small, que se sentia próximo de Lester Ward e de Gustav Ratzenhofer -, os integrantes de Chicago absorveram as críticas formuladas por Franz Boas a essa corrente do pensamento social e distanciaram-se da tarefa de levar adiante o projeto evolucionista. Tampouco mostraram grande entusiasmo com a prática de refletir abstratamente sobre as condições de progresso social e, ao contrário disso, trilharam um caminho no qual a reflexão teórica encontrava-se empiricamente enraizada. Mantendo uma inclinação política reformista aliada com uma filosofia pragmática, os sociólogos de Chicago procuraram transformar a sociologia numa ciência empírica, concentrando a atenção em determinados problemas sociais da vida urbana na qual estavam inseridos e em processos sociais, tais como organização e desorganização social, conflito e acomodação, movimentos sociais e mudanças culturais, buscando interligar a investigação dessas questões com a disposição de impulsionar reformas sociais no contexto de uma sociedade liberal-democrática (CAREY, 1975; HOFATADTER, 1944). 
Ao contrário do trabalho solitário e isolado realizado por determinados autores clássicos no processo de formação da sociologia europeia e americana, que, de forma geral, tiveram frágeis nexos com a instituição universitária, a produção de conhecimento levada a efeito no interior do Departamento de Sociologia de Chicago rompeu com essa modalidade de construção de trabalho intelectual. Desde o início, desenhou-se e implantou-se, no interior do Departamento, uma concepção de trabalho acadêmico que seria coduzido coletivamente, no qual ocorreria uma intensa colaboração entre os diversos membros do corpo docente e contaria também com ativa participação dos estudantes nos projetos de pesquisa. Embora as figuras de William Thomas e posteriormente de Robert Park ocupassem uma posição de destaque, o Departamento não chegou ser dominado acadêmica e intelectualmente por nenhum de seus docentes, de tal modo que a prática da sociologia foi concebida, desde o início de suas atividades, como um projeto institucional. Um dos traços distintivos que marcou a trajetória do Departamento, nos anos 1920, foi uma profícua relação entre a realização de pesquisas empíricas com ideias sociológicas, de tal forma que gradativamente organizou-se um programa de trabalho intelectual que procurou integrar teoria e pesquisa empírica. Num momento em que as fronteiras entre as disciplinas que constituem o universo das ciências sociais não haviam sido estabelecidas, os integrantes do Departamento de Chicago estabeleceram um constante diálogo com a filosofia, antropologia, educação e psicologia social e, através dessa postura, imprimiram uma dimensão interdisciplinar no trabalho intelectual, característica essa que contribuiu de forma significativa para o enriquecimento de suas pesquisas sociológicas (DINER, 1975, p. 514-553; LASWELL, 1971, p. 416-428).

Na visão de Albion Small, a sociologia deveria adquirir um rigor teórico e desfrutar de uma credibilidade científica alcançada pela economia para realizar uma contribuição no processo de reforma social, ou seja, deveria, para tanto, produzir pesquisadores. Juntamente com George Vincent, escreveu um handbook, denominado An Introduction to the Science of Sociology, com o propósito de construir um guia de pesquisa visando transformar Chicago em um laboratório de pesquisa sociológica. Albion Small desejava construir uma "história natural" de Chicago, capaz de apreender empiricamente os processos sociais subjacentes à distribuição de sua população no espaço urbano de Chicago, as formas de conflitos e de acomodação que brotavam dessa distribuição espacial. O trabalho de reforma social desenvolvido por Jane Adms no contexto da Hull House - cujo estabelecimento Albion Small frequentava na companhia de William Thomas, George Herbert Mead e Charles Henderson - produziu mapeamentos da cidade que forneceram importantes informações sobre sua estrutura espacial e social e o impactou profundamente. Por duas décadas - ou seja, antes da chegada de Robert Park e de Ernest Burgess -, Albion Small enfatizou a necessidade de 
explorar temas que ficaram intimamente associados ao acervo de investigação da escola de Chicago, tais como segregação racial, vivência étnica e religiosa de seus habitantes, a formação de profissionais para a administração pública, etc. Não menos importante foi sua iniciativa no sentido de criar, em 1895, o American Journal of Sociology, que constitui o primeiro periódico profissional da área e exerceu um papel importante no processo de institucionalização da sociologia norte-americana e na apresentação de sociólogos europeus até então pouco conhecidos, como foi o caso de Simmel, que teve mais de uma dezena de artigos traduzidos pelo próprio Small. As funções administrativas assumidas por Small talvez tenham contribuído para ofuscar sua contribuição intelectual, pois desempenhou um papel importante na trajetória de uma especulação abstrata sobre a evolução das sociedades para uma investigação empírica e uma analíse das relações entre grupos sociais (ABBOTT, 1999; HERBST, 1959; SMALL \& VINCENT, 1894; SMALL, 1905).

O pioneiro trabalho, The Polish Peasant in Erurope and America, que combinou de forma exitosa um exaustivo material empírico com uma reflexão teórica, publicado por William Thomas e Florian Znaniecki, entre 1918-1920, marcou simbolicamente o início de uma nova etapa na trajetória da sociologia norteamericana. Na visão de ambos, a sociologia deveria assumir a tarefa de examinar os diferentes níveis da organização social visando compreender como as regras sociais - nem sempre visíveis para os indivíduos em seus comportamentos cotidianos - que estruturam as diferentes organizações sociais contribuem para regular as condutas dos inivíduos. O minucioso trabalho realizado por Thomas e Znaniecki enfocou, em uma perspectiva comparativa, processos de mudança social que ocorreram na Polônia e nos Estados Unidos durante o século XIX e início do século XX e analisou estruturas sociais, econômicas e culturais que conduziram os imigrantes a cruzarem o Atlântico e que estiveram presentes na (re)configuração de suas vidas e personalidades no contexto urbano de Chicago. Nesse sentido, investigaram uma multiplicidade de temas, tais como natureza da família dos camponeses poloneses, sua estrutura familiar, o sistema de classe social, a vida econômica, religiosa e cultural, explorando as relações entre processos de organização e desorganização social nas vidas e na constituição da personalidade dos camponeses poloneses. Trata-se de uma história de camponeses cujo mundo social encontra-se em processo de dissolução, cujos valores e normas éticas se desfazem ao serem confrontados na inserção de uma sociedade complexa, marcada por relações impessoais (THOMAS, 1966; THOMAS \& ZNANIECKI,1984).

A adesão de William Thomas ao projeto de reforma social aproximou-o da população de migrantes e de camadas pobres que frequentavam a Hull House comandada por Jane Adams e impulsionou-o a desempenhar um papel ativo 
na Juvenile Protective Association e no Imigrant's Protective League, o que lhe permitiu obter um considerável volume de informações empíricas. Sua partcipação no movimento de reforma social levou-o a realizar um dos trabalhos sociológicos pioneiros sobre gênero, Sex and Society, no qual, a partir de seu enfoque de interligar o sistema de personalidade com a organização social, examinou o papel desempenhado pelo gênero na formação da personalidade feminina, ressaltando sua posição dominada ao longo do tempo. William Thomas participou ativamente nos movimentos em favor do voto feminino e dos direitos civis para camadas da população que deixaram a condição de escravidão (JANOWITZ, 1966, p. vii-viii; VOLKART, 1951).

A precoce e controvertida saída de William Thomas do Departamento, em 1918, não interrompeu o ímpeto de realização de trabalhos de investigação sobre a cidade de Chicago, que foram continuados sob a égide de Ernest Burguess e de Robert Park. O primeiro deles obteve seu doutorado no próprio Departamento, em 1913, e tornou-se seu docente, em 1919, permanecendo no seu interior até 1957. Robert Park cursou filosofia em Harvard e na Alemanha, participou nos movimentos de reforma social, exerceu por longos anos a atividade de jornalista e foi levado para o Departamento através de Thomas, quando tinha mais de cinquenta anos de idade. Sua presença desempenhou grande influência na vida acadêmica do Departamento até sua aposentadoria, em 1933. Robert Park, consoante com o espírito investigativo que existia no Departamento, pretendia fornecer uma sólida base empírica para a investigação sociológica, aliada com uma reflexão teórica com vistas a contribuir para a discussão pública de questões candentes pertinentes a uma sociedade urbana-industrial. A presença de Robert Park e de Enest Burgues - que compartilhavam um gabinete de trabalho no Social Science Research Building - inspirou uma geração de doutorandos a pesquisar a cidade de Chicago, procurando captar os padrões de organização de suas instituições sociais. Na visão de Park, o processo de industrialização corroeu a separação social entre o mundo rural e o urbano, uma vez que suas consequências sociais influenciam igualmente as relações sociais em ambos os contextos espaciais. No entanto, em sua perspectiva, a cidade expressava, com maior intensidade, os efeitos decorrentes do processo de industrialização nas sociedades modernas e constituía um verdadeiro laboratório para estudar as sociedades humanas (JORGENSEN \& SMITH, 2009).

Motivado a pesquisar a distribuição espacial e social dos grupos na cidade de Chicago, Robert Park publicou um longo artigo intitulado The City, no qual procurou desenvolver a abordagem da ecologia humana, ressaltando que a regularidade do processo urbano e da vida social desenvolvido no seu ambiente, entre os quais ressaltou a segregação social e a mobilidade espacial, constitui fenômeno relevante na produção de padrões de impessoalidade existentes 
no contexto urbano. Esse artigo delineou o programa de pesquisas sobre o espaço urbano que foi realizado por vários integrantes do Departamento de Chicago. Tal como Simmel, percebia diferenças entre as culturas existentes nos espaços urbano e rural, no entanto, acentuava a diversidade de manifestações culturais no ambiente urbano, decorrentes da variada composição social de sua população, destacadamente a que podia ser observada na cidade de Chicago. Na visão de Park, a ecologia humana, ao analisar a segregação demográfica e a expansão física, possibilitava também analisar os processos de interação social, uma vez que ela encontra-se inserida na dinâmica da vida urbana (PARK, 1915, p. 577612).

No estudo do espaço urbano, Robert Park recomendava a utilização de mapping e de técnicas que vinham sendo empregadas pela antropologia no estudo de culturas localizadas em outros continentes. De acordo com ele, o espaço urbano poderia ser estudado como um laboratório, de tal forma que a sociologia poderia estudar os indivíduos e suas relações sociais em seu ambiente natural, em contraste com os laboratoriais experimentos nos quais os pesquisadores isolam fenômenos e/ou seres humanos com o propósito de investigar suas reações diante de estímulos artificias. A diversidade de estilos de vida existente na cidade de Chicago, que impelia socialmente os imigrantes europeus, os migrantes, bem como seus habitantes nativos a reverem seus estilos de vida, deveria ser estudado, na visão de Park, através de um contato direto do investigador com seu objeto de estudo. Nesse contexto, surgiram trabalhos que se tornaram clássicos no repertório da escola de Chicago e a projetaram internacionalmente, tais como os realizados por Nels Anderson, Paul Cressey, Edwin Trasher, Ruth Cavan, Louis Wirth, entre outros. Além dos métodos ecológicos desenvolvidos por Park, várias técnicas de pesquisa foram utilizadas, tais como observação de campo, entrevista, coleta de casos, etc. Os sociólogos de Chicago estavam mais interessados em desenvolver e introduzir novas técnicas de pesquisa empírica no campo da sociologia - fenômeno este que constituía uma novidade na disciplina - do que formalizar procedimentos e regras de investigação, o que explica a ausência da produção de trabalhos metodológicos realizados pelos seus integrantes (ABBOTT, 1999).

Ao contrário da interpretação que procura assinalar o caráter ateórico e ressaltar a inclinação empiricista do Departamento de Sociologia de Chicago, a agenda de trabalho desenvolvida no seu interior indica o interesse de seus docentes e alunos pelos movimentos intelectuais existentes no contexto do pensamento social. Nesse sentido, travaram um conhecimento com pensadores norte-americanos e também europeus, entre os quais Durkheim, Simmel, Weber, Pareto, Mauss, etc. Destacadamente, possuíam um interesse pela filosofia pragmática que procurava afastar o conhecimento de uma reflexão metafísica e, 
simultaneamente, direcioná-lo para a pesquisa científica. Ao incorporarem determinadas formulações elaboradas pela filosofia pragmática, destacadamente as contribuições de John Dewey e George Herbert Mead, os sociólogos do Departamento de Chicago procuraram oferecer um substrato empírico às suas reflexões sobre questões relativas à ação social desenvolvida pelos indivíduos. O pressuposto que os pesquisadores deveriam oferecer, através de suas investigações, uma colaboração na formulação de política social, assumido em larga medida pelos sociólogos de Chicago, derivava da crítica da filosofia pragmática ao postulado da dúvida radical de Descartes e sua substituição pela busca do conhecimento visando enfrentar problemas concretos da sociedade, que experimentava um rápido processo de industrialização e urbanização. A ênfase da filosofia pragmática na indissociabilidade entre pensamento e ação, da necessidade de articular reciprocamente teoria e mundo real, marcou o estilo de trabalho intelectual desenvolvido no Departamento de Sociologia de Chicago e imprimiu uma relativa unidade entre seus participantes diante do processo de investigação e os conduziram a se distanciar deliberadamente de uma reflexão abstrata sobre questões teóricas e conceituais existente no escopo da disciplina (SHILS, 1980).

A influência do prgamatismo na sociologia desenvolvida no Departamento de Chicago deve-se, em grande medida, aos ensinamentos e trabalhos desenvolvidos por John Dewey e George Herbert Mead. Existiu uma significativa interação intelectual e pessoal entre os sociólogos do Departamento de Chicago e os filósofos pragmatistas: Albion Small, William Thomas e Charles Herderson frequentavam as discussões sobre reforma social que ocorriam na Hull House na companhia de G. H. Mead; Robert Park foi aluno de graduação de John Dewey na Universidade de Michigan; Ellsworth Faris, durante seu doutorado em psicologia na Universidade de Chicago, realizou cursos sob a responsabilidade de John Dewey, George Herbert Mead e James Angell e, como docente do Departamento, manteve a tradição da psicologia social desenvolvida por G. H. Mead.

A interpretação dos processos psíquicos que os indivíduos utilizam para solucionar problemas no curso de suas ações esteve no cerne das preocupações intelectuais de John Dewey. Sua crítica dirigia-se a uma tradição existente na psicologia que analisava de forma segmentada as operações psíquicas realizadas pelos indivíduos, uma vez que a compreendia ao longo de uma cadeia que envolvia estimulações externas, processamento interno e, por fim, a reação do indivíduo às condições externas provenientes do ambiente imediato que o permeava. Em sua perspectiva, ao contrário desse modelo explicativo, é a própria dinâmica de uma determinada ação realizada pelo indivíduo que condiciona os estímulos relevantes que a circunscreve. Ao centrar sua crítica nas teorias que reduzem a ação a um conjunto de reflexo de estímulos ambientais, 
procurava destacar que é problemático sustentar que a determinação de um fim de uma ação seja um ato consciente do indivíduo e um elemento exterior à própria dinâmica da ação em curso, pois, em sua visão, a determinação de um fim de uma ação específica só pode ser constituída através de considerações sobre as resistências que uma conduta encontra durante sua realização (DEWEY, 1922).

A influência de George Herbert Mead foi marcante na existência do Departamento de Chicago, não apenas na década de 1920, mas estendeu-se também em períodos posteriores através da atuação de Ellsworth Faris e de Herbert Blumer, que foram seus estudantes e seguidores de suas ideias, e que teve um impacto decisivo na emergência e desenvolvimento da formação do interacionismo simbólico. Tal como John Mead, também irá formular uma crítica às teorias existentes na psicologia que explicavam a ação dos indivíduos através de estímulos externos, especialmente ao behaviorismo, com quem teve uma relação complexa, uma vez que, ao mesmo tempo em reconhecia seus méritos na explicação da conduta humana, procurou salientar seus limites explicativos. Por um lado, era sensível às colocações dos behavioristas no que diz respeito às recompensas e custos da ação. No entanto, o que incomodava intelectualmente Mead era o fato de o behaviorismo excluir o estudo da consciência do ator, na medida em que considerava que ela não era acessível empiricamente à abordagem científica. Na perspectiva de Mead, os seres humanos eram distintos de outras criaturas, uma vez que são dotados de consciência. Em sua perspectiva, os símbolos significantes permitem aos atores compartilharem significados e, a partir daí, estabelecerem uma comunicação entre eles, destacando que a interação entre os indivíduos envolve um complexo processo de interpretação, na medida em que procuram refletir constantemente e interpretar continuamente as palvras e gestos do outro. Destacava que o ator procura também comprender o contexto da situação na qual se encontra momentaneamente inserido. A partir de insights de John Dewey, Mead ressalta a relação recíproca entre indivíduo e sociedade - que até então, na sociologia norte-americana, eram percebidos como entidades separadas - e concebe a mente humana como o produto de um ativo processo de interação social, de tal forma que, em sua visão, os indivíduos percebem o mundo e se situam nele na medida em que se colocam no papel do outro (taking the role of the other). Nesse processo, na percepção de G. H. Mead, os indivíduos desenvolvem também a capacidade de conversarem consigo próprios, ou seja, de interpretarem sua própria ação durante a realização de uma interação com outros indivíduos. Consoante com a filosofia pragmática, que acentuava a relação recíproca entre sujeito e objeto do conhecimento, G. H. Mead, ao assinalar que os atores possuem consciência e capacidade interpretativa, vislumbrava sua capacidade de possuir uma interação dinâmica com a realidade. Sua análise do comportamento humano permitiu perceber que os 
seres humanos agem diante da realidade que os cerca, ou seja, diante de objetos físicos, ideias, instituições, atividades, com base nos sentidos que as coisas apresentam para eles, sendo que o sentido que os seres humanos atribuem à realidade emerge do próprio processo interacional (MEAD, 1934, 1964; MELTZER, 1959).

\section{Considerações finais}

O conjunto de pesquisas e reflexões empreendidas pelos participantes do Departamento de Sociologia de Chicago na década de 1920 concentraram a atenção em determinados eixos temáticos, entre os quais destacam-se o processo de organização social, ecologia social e psicologia social. Os estudos de organização social, impulsionados pelo trabalho The Polish Peasent in Europe and America, de William Thomas e Florian Znaniecki, abordaram uma pluralidade de universos sociais, movendo-se da análise de grupos primários a estudos de comunidade, enfocando organizações de larga escala social, como o sistema econômico, educacional, imprensa, associações voluntárias, procurando desvendar as propriedades constitutivas de cada um desses contextos particulares. As pesquisas realizadas sob a perspectiva da ecologia humana, levada adiante por Robert Park, Ernest, Burguess, Edwin Trasher e Harvey Zorbaugh, ao enfatizarem a relação entre espaço urbano e vida social, acentuaram os processos de competição, conflito e acomodação existentes na cidade de Chicago e seu respectivo impacto no processo de comportamento dos indivíduos. As reflexões realizadas em torno de questões relativas à psicologia social efetuadas por George Herbert Mead, John Dewey, Charles Cooley, Ellsworth Faris, entre outros, ofereceram contribuições significativas para repensar as mediações que permeiam as relações existentes entre indivíduo e sociedade. Nenhum desses eixos temáticos exerceu um domínio acadêmico absoluto no interior do Departamento de Sociologia de Chicago; ao contrário dessa tendência, não seria incorreto afirmar que ocorreu uma íntima conexão e fluidez intelectual entre essas interfaces de investigação.

Dessa forma, os trabalhos desenvolvidos no interior do Departamento de Sociologia de Chicago, na década de 1920, dificilmente pode ser enquadrado num paradigma sociológico unívoco, uma vez que seus participantes jamais reivindicaram a inserção numa vertente teórica no contexto da sociologia. Deve-se destacar também que o termo interacionismo simbólico tampouco foi utilizado pelos seus docentes e alunos para designar a atividade intelectual que estavam realizando. $O$ conjunto de trabalhos realizados - que na maioria das vezes integrava uma abordagem etnográfica com uma reflexão teórica - contribuiu para a compreensão da complexidade da interação entre as mudanças que vinham ocorrendo na cidade de Chicago e seu impacto nas experiências concretas 
nas vidas dos indivíduos e na formação de suas personalidades, de tal forma que forneceram contribuições metodológicas relvantes para integrar os níveis macro e micro da vida social. Apesar de não direcionar suas pesquisas e reflexões na construção de uma nova abordagem teórica, o resultado do empreendimento intelectual levado a efeito pelos sociólogos de Chicago na década de 1920 forneceram elementos empíricos e teóricos que permitiram embasar determinados pressupostos da corrente interacionista que foi edificada e codificada em um período posterior.

A relação recíproca entre indivíduo e sociedade, que constitui um pressuposto central desenvolvido pela análise interacionista, foi amplamente explorada pelos trabalhos levados a cabo pelos participantes do Departamento de Sociologia de Chicago. Certamente, constiui um truísmo no panorama atual das ciências sociais ressaltar a interpenetração entre os diferentes contextos sociais e o comportamento cotidiano dos indivíduos. No entanto, no período em que os integrantes do Departamento de Chicago estavam elaborando seus trabalhos, predominava na sociologia norte-americana uma orientação que abordava o indivíduo e a sociedade como unidades metodologicamente distintas e separadas teoricamente. Na perspectiva individualista - então predominante no contexto da sociologia norte-americana -, a sociedade era compreendida como um agregado de indivíduos cujos comportamentos, em larga medida, eram impulsionados por mecanismos biológicos, derivados por estruturas físicas da mente humana, ou comandados por respostas instintivas do ser humano diante do estímulo do meio circundante. Nessa direção, a sociedade era percebida como um elemento antagônico, que restringia potencialmente as tendências naturais do ser humano. Ao distanciar da perspectiva que enfocava a sociedade como resultado de motivações internas dos indivíduos ou de fatores externos, os trabalhos desenvolvidos pelos sociólogos do Departamento de Chicago colocaram em evidência a importãncia de proceder uma análise meticulosa dos contextos e situações sociais concretas nas quais ocorrem o comportamento humano.

O trabalho de Charles Cooley, Human Nature and Social Control, destacou a importância da mediação do grupo social, particularmente dos grupos primários, no processo de socialização dos indivíduos e de seu efeito na dinâmica da complexa interação existente entre os indivíduos e a sociedade. Em sua perspectiva, compartilhada por vários integrantes do Departamento de Sociologia de Chicago, o grupo social era portador de um conjunto de significados e de códigos sociais produzidos no próprio processo de interação. Em sua visão, o compartilhamento de códigos produzidos no interior de um determinado grupo cria condições e motivações favoráveis para o comportamento dos indivíduos na sociedade e contribuem para localizar o indivíduo e seus parceiros num amplo sistema de relações sociais, de tal forma que, na concepção de Charles 
Cooley, indivíduo e sociedade constituem dois lados da mesma moeda. As formulações dos sociólogos de Chicago destacaram a dimensão subjetiva da vida social, uma vez que colocaram em evidência o caráter ativo dos indivíduos, acentuando sua capacidade de pensar, perceber, julgar, opinar, formular projetos de vida e construir suas indentidades pessoais. Ao mesmo tempo, ao analisar variados tipos de instituições sociais, ao abordar a regulação do espaço urbano, ao enfocar a existência de valores e regras que regulam as relações sociais, destacaram também a dimensão objetiva da vida social. Na análise da relação entre contextos sociais e indivíduos, entre organizações sociais e sistemas de personalidade, utilizaram uma perspectiva mais processual que estrutural, ou seja, destacaram que a existência de diferentes tipos de organizações macrossociais são criadas, mantidas e modificadas pela atividade humana, através de interações recíprocas que os indivíduos estabelecem entre si, de tal modo que as interações sociais criam, mantém e recriam a dimensão objetiva da vida social (COOLEY, 1964).

O pressuposto da dimensão simbólica e interpretativa da vida social, que informou posteriormente a análise interacionista, encontra-se subjacente nos trabalhos desenvolvidos no Departamento de Chicago na década de 1920. Ao se distanciarem da concepção que abordava a sociedade como um somatório de indivíduos que se agregavam para enfrentar as limitações do meio físico - em voga na sociologia norte-americana da época -, os integrantes do Departamento de Chicago destacaram que a sociedade é construída através do compartilhamento de um amplo conjunto de significados culturais e sociais entre os seus participantes. Nesse sentido, os trabalhos e reflexões efetuados destacaram o papel da aprendizagem das normas sociais, de tal forma que os indivíduos criam habilidades que lhes permitem passar de disposições cognitivas gerais à compreensão de fatos particulares, a utilizar os recursos da linguagem, a expressar e a compreender gestos não verbais no processo de interação social. Na visão dos sociólogos de Chicago, a aprendizagem ao longo da existência de um amplo espectro de códigos sociais permite aos indivíduos situarem-se diante do mundo, classificarem objetos em categorias compreeníveis para si e para os demais participantes de um processo interacional, adotarem disposições mutuamente previsíveis em um determinado contexto social, de tal forma que, elaborando a significação de sua conduta, o indivíduo é, ao mesmo tempo, elaborada por ela.

Ao acentuar que os indivíduos são atores de sua existência e não um mero agente que comporta através de reações a um conjunto de regras e valores sociais exteriores, vários trabalhos realizados no interior do Departamento de Chicago abriram um flanco para a reflexão sobre a dimensão interpretativa que os indivíduos utilizam diante das situações nas quais se encontram inseridos. As reflexões de George Herbert Mead, John Dewey e Charles Cooley sobre o 
papel ativo e reflexivo da consciência dos indivíduos no processo social representaram contribuições relevantes para a compreensão da dimensão interpretativa da vida social. Nessa direção, ao definir uma determinada situação social nos termos formulados por William Thomas, o indivíduo que a projetou encontra-se diante da incessante tarefa de interpretar sua dinâmica, ou seja, exercer um autocontrole sobre a imagem que criou de si mesmo para os demais participantes envolvidos no processo interacional e, ao mesmo tempo, interpretar constantemente as reações dos demais participantes diante de seu próprio comportamento. As reflexões de Charles Cooley contidas em seu livro Human Nature and the Social Order ofereceram contribuições teóricas para a compreensão do peso da dimensão interpretativa na vida social; seu conceito looking-glass-self destaca que os indivíduos formulam imagens, percepções e julgamentos sobre os outros em suas mentes, de tal modo que os indivíduos existem reciprocamente na mente do outro, fenômeno esse que conduziu Charles Cooley a salientar que a imaginação que as pessoas possuem umas sobre as outras constitui um sólido e significativo fato social.

O pressuposto de que as atividades humanans ocorrem em situações determinadas em tempo e espaço específicos que orientam a perspectiva interacionista também foi amplamente explorada pelos integrantes do Departamento de Sociologia de Chicago no período em foco. O empreendimento intelectual desenvolvido pelos seus docentes e alunos destacou que a compreensão de um fenômeno social particular envolve a tarefa metodológica de relacioná-lo com o lócus de sua produção, o esforço intelectual de articulá-lo com outros fenômenos sociais pertinentes à sua compreensão e contextualizá-lo numa perspectiva processual, ou seja, compreender a dinâmica do processo interacional que envolve sua produção, bem como a necessidade analisá-lo, interligando uma abordagem sincrônica com uma perspctiva diacrônica. Nessa perspectiva, os sociólogos de Chicago destacaram que os indivíduos encontram-se inseridos em contextos nacionais, culturais e institucionais e desenvolvem suas açõs cotidianas em variadas situações sociais, tais como em determinadas condições econômicas, familiares, grupos sociais particulares, relações raciais e encontram-se também diante de recursos espaciais, materiais e simbólicos específicos que constituem condições reais de seu comportamento na vida social.

Ao mesmo tempo em que salientaram o substrato objetivo da realidade social, expresso numa ampla gama de instituições sociais que permeiam as vidas e as personalidades dos indivíduos, seus trabalhos ressaltaram que as instituições que aparentam um elevado grau de estabilidade social encontram-se expostas também a um processo de mudança social, uma vez que são produzidas pela atividade humana. As análises de William Thomas chamaram a atenção a propósito da relação entre atitudes do indivíduo, ou seja, sua predisposição 
em agir, e a realidade objetiva na qual se encontra inserido. Nesse sentido, distanciou-se de uma perspectiva behaviorista que explicava o comportamento dos indivíduos em função de respostas ao estímulo provocado pelo ambiente. Em sua concepção, os indivíduos possuem um papel ativo diante da situação social na qual se encontram inseridos, uma vez que suas atitudes contribuem também para (re)definir uma determinada situação social. Suas elaborações colocaram em tela que se, por um lado, as diversas situações socias possuem um aspecto objetivo na estruturação do comportamento, possui também uma dimensão de instabilidade intrínseca, uma vez que o ponto de vista de cada ator constitui um elemento estratégio na construção da definição das situações sociais, conduzindo o indivíduo a avaliar continuamente as circunstâncias nas quais se encontra envolvido, e se posicionar num incessante e recíproco jogo de reavaliação e reajustamento com os demais participantes da situação. Em sua visão, a significação de um objeto ou de uma situação não reside apenas em sua manifestação objetiva, mas comporta também a dinâmica do processo interacional estabelecido entre seus participantes e nas possíveis (re)definições que podem ocorrer nas situações sociais.

No período pós-segunda guerra, o sistema universitário norte-americano experimentou uma significativa expansão que possibilitou a emergência de novos centros de ensino e de pesquisa. O Departamento de Chicago, que, através de suas pesquisas e reflexões, teve influência decisiva na organização institucional da disciplina, presença monopolista na publicação do American Journal of Sociology e dominou o campo da sociologia por um longo período, encontrou diante de si concorrrência de outros departamentos, particularmente os de Harvard e Columbia. A partida de Robert Park, ocorrida em 1934, recorrentemente, serve como um marcador simbólico que expressa o fim do apogeu acadêmico da fase inicial do Departamento de Sociologia de Chicago. No final dos anos 1930, a balança de poder acadêmico pendeu favoravelmente para o Departamento de Sociologia de Harvard, em cujo interior Talcott Parsons propôs um ambicioso projeto teórico estrutural-funcional visando analisar os elementos constitutivos do sistema da ação humana. O trabalho de Talcott Parsons, The Structure of Social Action, publicado em 1937, recorreu exclusivamente a pensadores europeus para formar seu quadro de referência analítica e não dedicou uma única menção ao desenvolvimento da filosofia pragmática desenvolvida por John Dewey e George Herbert Mead, e tampouco aos trabalhos de pesquisa realizados pelos pioneiros do Departamento de Sociologia de Chicago, apesar de conhecer a produção intelectual realizada no seu interior, uma vez que, em 1936, ministrou curso de verão nas suas dependências. Simultaneamente, o Departamento de Columbia, através da atuação de Paul Lazersfeld e Robert Mertom, passou a desenvolver sofisticadas técnicas de investigação quantitativa no campo da sociologia, coroando o esforço de Franklin Giddings que, durante o extenso 
período que esteve na direção do Departamento de Columbia, ou seja, entre a metade de 1890 até 1920 , trabalhou ativamente para incorporar métodos estatísticos na análise sociológica (CAMIC, 1996; FINE,1995, p 1-16)

Apesar da emergência de novos centros dominantes no contexto da sociologia norte-americana, o legado intelectual dos pioneiros do Departamento de Sociologia foi levado adiante por uma nova geração de docentes, entre os quais destacam Louis Wirth, Everett Hughes, Loyd Warner, Anselm Strauss, Robert Redfield, entre outros. Apesar das diferenças intelectuais existentes, eles compartilhavam um estilo de trabalho sociológico inaugurado pelos seus predecessores, ou seja, uma disposição de realizar exaustivos trabalhos de campo com o propósito de compreender minuciosamente as ações humanas, uma atenção especial para as circunstâncias concretas nas quais ocorrem a trama da atividade dos indivíduos, um sentimento de ceticismo com relação a uma teorização abstrata sobre a vida social, uma descrença com relação à eficácia de elaboração de tratados formais sobre procedimentos metodológicos, uma refinada atitude de ironia e irreverência intelectual com relação ao mundo oficial e seus representantes legais. Herbert Blumer, um ex-aluno de George Herbert Mead, que integrava também esse grupo de docentes, assumiu a tarefa de sistematizar e codificar o legado intelectual de determinados aspectos do trabalho realizado pelos pioneiros do Departamento de Sociologia na década de 1920. Nesse sentido, destacou as significativas contribuições dos seus trabalhos para compreender a capacidade criativa da atividade humana diante do mundo social, a dimensão autorreflexiva utilizada pelos indivíduos diante das situaçãoes sociais, o incessante aspecto interpretativo realizado pelos indivíduos durante os processos interacionais, a orientação de inserir a análise do comportamento humano em tempo e espaço específicos como condição sine qua non de sua inteligibilidade e integrou essas orientações que se encontravam subjacentes no trabalho desenvolvido pelo Departamento de Chicago, em um corpus teórico designado por ele em 1937 de interacionismo simbólico que, a partir de então, se expandiu, diversificou-se internamente e integrou-se ativamente no panorama metodológico e teórico das ciências sociais contemporâneas.

Abstract: The article highlights that the participants from the Chicago Department of Sociology in the twenties did not have the intention of creating a new sociological approach.The concept of Symbolic Interacionism has never been used to assign the works that were being accomplished by the participants. Therefore, the empirical research and the thought used inside that Department related to the process of interaction between individual and society have opened the way for a new explanation of social life in a later moment. Only at the end of the decade, 1930, the sociological work that had been accomplished in that Department was codified in a corpus of theoretical principles 
and nominated symbolic interactionism.

Keywords: Chicago Department of Sociology, Empirical Research and Theory, Relation Individual and Society, Symbolic Interactionism.

\section{Referências}

ABBOTT, Andrew. Department \& Discipline. Chicago Sociology at the One Hundred. Chicago: The University of Chicago Press, 1999.

BLUMER, Herbert. Symbolic Interacionism: Perspective and Method. University of California Press, 1986.

BRANDÃO LOPES, Juarez. "A Escola de Chicago ontem e hoje: um depoimento pessoal", In: Lícia do Prado Valladares (Org.) A Escola de Chicago: impacto de uma tradição no Brasil e na França. Editora UFMG. Belo Horizonte, 2005.

CALHOUM, Craig. "Sociology in America: an introduction", In: Craig Calhoum (Org.) Sociology in America: A History. Chicago: The University of Chicago Press, 2007.

CALHOUM, Craig \& VAN Antwerpen. "Ortodoxy, Heterodoxy and Hierarchy: 'Mainstream 'Sociology and its Challengers", In: Craig Calhoum (Org.) Sociology in America: A History. Chicago: The University of Chicago Press, 2007.

CAMIC, Charles. "Three Departments in Search of a Discipline: Localism and Interdisciplinary Interaction in American Sociology, 1890-1940". Social Research. Vol. 62(4). 1996.

CAREY, James. Sociology and Public Affairs: the Chicago Scholl. Beverly Hills: Sage, 1975.

CLARK, Terry. Prophets and patrons: the french university and the emergence of social sciences. Massachussetts: Harvard University Press, 1973.

CHAPOULIE, Jean-Michel. La Tradition Sociologique de Chicago (1892-1961). Paris: Seuil, 2001.

COLLOMY, Paul \& BROWN, David. "Elaboration, Revision, Polemic and Progress in the Second Chicago School", In: Gary Fine (Org.) A Second Chicago School? The Development of a Postwar American Sociology. Chicago: The University of Chicago Press, 1984.

COOLEY, Charles Horton. Human Nature and Social Order. New York: Schocken Books, 1964. 
DEWEY, John. Human Nature and Conduct: An Introduction to Social Psycology. Henry Holt \& Co.

DINER, Steven. "Department and Discipline: the Department of Sociology at the University of Chicago". Minerva, 13 p. 514-553, (Winter), 1975.

FINE, Gary. "A Second Chicago School? The development of a postwar American sociology". In: Gary Fine (Org.) A Second Chicago School? The development of a postwar American sociology. Chicago: The University of Chicago Press.

. "The sad demise, mysterious disappearance and glorious triumph of symbolic interactionism". Annual Review of Sociology, 1993 (61), p. 61-87.

FISHER, Berenice \& Strauss, Anselm. "Interactionism", In: Tom Bottomore \& Robert Nisbet (Org.). A History of Sociological Analysis. New York: Basic Books, 1978.

FARIS, Robert. Chicago Sociology (1920-1932). Chicago: University of Chicago Press, 1967.

GOULDNER, Alvin. The Coming Crisis of Western Sociology. New York: Basic Books, 1970.

GEIGER, Roger. To Advance Knowledge: the growth of American research universities (1900-1940). New York: Oxford University Press, 1986.

GUSFIELD, Joseph. "The Second Chicago School", In: Gary Fine (Org.) A Second Chicago School? The Development of a Postwar American Sociology. Chicago: The University of Chicago Press, 1995.

HARVEY, Lee. Myths of the Chicago School of Sociology. Avebury: Albershot, 1987.

HERBST, Jurgen. "From Moral Philosophy to Sociology: Albion Small". Harvard Educational Review, n. 29 (Summer), p. 227-44, 1959.

HOFSTADTER, Richard. Social Darwinism in America Thought. Boston: Beacon, 1944.

JANOWITZ, Morris. (org.) W. I. Thomas on Social Organization and Personality: select papers. Chicago: University of Chicago Press, 1966.

KALBERG, Stephen. "A Cross-National Consensus on a Unified Sociological Theory? Some Inter-Cultural Obstacles". European Journal of Social Theory. 10(2). 2007. 
KURTZ, Lester. Evaluating Chicago Sociology. Chicago: University of Chicago Press, 1984.

LASSWELL, Harold. "The Cross-Disciplinary Manifold: the Chicago Prototype", In: Alfred Lepawsky \& Edward Buerhrig (org.). Search for World Order. New York: Appleton-Century-Crofts, 1971.

LEWIS, David \& SMITH, Richard. American Sociology and Pragmatism: Mead, Chicago and Symbolic Interaction. Chicago: University Chicago Press, 1980.

LUCAS, Christopher. American Higher Education and History. New York: St. Martin's Griffin, 1994. MAYER, Harold \& WADE, Richard. Chicago: growth of a metropolis. Chicago: University of Chicago Press, 1969.

MEAD, George Herbert. Mind, Self and Society: From the Standpoint of a Social Behaviorist. Chicago: University of Chicago Press, 1934.

Press, 1964.

On Social Psycology: Select Papers. Chicago: University of Chicago

MELTZER, Bernard. The Social Psycology of George Herbert Mead. Kalamazoo, Michigan: Center for Sociological Research, 1959.

PARK, Robert. "The city: suggestions for the investigation of human behavior in the city environment". American Journal of Sociology, 20 (5), 1915.

RIESMAN, David. Constraint and variety in American Education. New York: Gardent, 1958.

REUBEN, Julie. The Shaping of the modern university. Chicago: University of Chicago Press, 1995.

RINGER, Fritz. The decline of the mandarins: the German academy community (1890-1993). Cambridge: Harvard University Press, 1969.

SCHWENDINGER, Hernam \& SCHWENDINGER, Julia. Sociologist of the Chair. New York: Basic, 1974.

SHILLS, Edward. "The University, the city and the world: Chicago and the University of Chicago", In: Thomas Bender (Org.). The University and the city: from medieval origins to the present. Oxford: Oxford University Press, 1988.

. The Calling of Sociology and Other Essays on the Pursuit of Learning. Chicago: University of Chicago Press, 1980. 
SMALL, Albion. General Sociology: an exposition of the main development in sociological theory from Spencer to Tatzenhofer. Chicago: University of Chicago Press, 1905.

SMALL, Albion \& VINCENT, George. An Introduction to the Study of Society. New York: American Book Company, 1894.

SMITH, Denis. The Chicago School: a liberal critique of capitalism. New York: St. Martin's Press, 1988.

\& JORGENSEN, Ana. The Chicago School of Sociology, in: Encountering the Everyday: an introduction to the sociologies of the unnoticed. New York: Palgrave Macmillan, 2009.

SNOWN, David \& DAVIS, Phillip. "The Chicago Approach to Collective Behavior", In: A Second Chicago School? The Development of a Postwar American Sociology. Chicago: University of Chicago Press, 1995.

STOR, Richard \& BUNNET, Virgil. Harpe's University. Chicago: University of Chicago Press, 1966.

THOMAS, William. On Social Organization and Social Personality. Chicago: The University of Chicago Press, 1966.

\& ZNANIECKI, Florian. The Polish Peasent in Europe and America.

Chicago: University of Illinois Press, 1984.

VELHO, Gilberto. "Reflexões sobre a Escola de Chicago", In: Licia do Prado Valladares (Org.) A Escola de Chicago. Impacto de uma tradição no Brasil e na França. Belo Horizonte: Editora UFMG, 2005.

VOLKART, Edmund. Social behavior and personality: contributions of W. I. Thomas to Theory and Social Research. New York: Social Science Research Council, 1951. 